Волгоградский институт управления - филиал РАНХиГС г. Волгоград, Российская Федерация

А. Е. Гончарова

Волгоградский государственный технический университет

2. Волгоград, Российская Федерация

\title{
ОБОСНОВАНИЕ ЭФФЕКТИВНОСТИ ПРОЦЕССОВ СЛИЯНИЙ И ПОГЛОЩЕНИЙ НА ФАРМАЦЕВТИЧЕСКОМ РЫНКЕ: МИРОВОЙ ОПЫТ И РОССИЙСКАЯ СПЕЦИФИКА
}

\begin{abstract}
АНнотАция. Изучение методов оценки эффективности процессов по слияниям и поглощениям до сих пор остается актуальным, а реализация существующих подходов в практической деятельности компаний требует теоретического обоснования. Проведение анализа по сделкам слияний и поглощений в масштабе мирового фармацевтического рынка является актуальным, так как результатом подобных процессов являются структурные преобразования, приводящие к изменению расстановки сил среди участников рынка, изменению ценовых и маркетинговых стратегий. По причине социальной значимости фармацевтического рынка, происходящие преобразования влияют на доступность лекарственных средств для потребителей. В данной статье рассмотрена методика оценки эффективности сделок по слияниям и поглощениям, а также методы оценки стоимости компаний. Проанализирован мировой рынок слияний и поглощений на фармацевтическом рынке в 2000-2016 гг. и рассмотрена российская специфика.

кЛЮчЕВЫЕ слОВА. Слияния и поглощения; оценка эффективности; фармацевтический рЫнок.

ИНФОРМАЦИЯ О СТАТЬЕ. Дата Поступления 31 октября 2017 г.; дата принятия к печати 19 декабря 2017 г.; дата онлайн-размещения 29 декабря 2017 г.
\end{abstract}

A. V. Evstratov

Volgograd institute of management, branch of RANEPA, Volgograd, Russian Federation

A. Ye. Goncharova

Volgograd state technical university, Volgograd, Russian Federation

\section{SUBSTANTIATION OF EFFICIENCY OF MERGERS \\ AND ACQUISITIONS PROCESSES IN THE PHARMACEUTICAL MARKET: WORLD EXPERIENCE AND RUSSIAN SPECIFICITY}

\begin{abstract}
The study of methods for assessing the effectiveness of processes for mergers and acquisitions is still relevant, and the implementation of existing approaches in the practical activities of companies requires a theoretical justification. The analysis of M\&A transactions on the scale of the world pharmaceutical market is relevant, as the result of such processes are structural transformations that lead to a change in the alignment of forces among market participants, changes in price and marketing strategies. Due to the social importance of the pharmaceutical market, ongoing changes affect the availability of medicines to consumers. This article examines the methodology for assessing the effectiveness of mergers and acquisitions, as well as methods for assessing the value of companies. The world market of mergers and acquisitions in the pharmaceutical market in 2000-2016 is analyzed and Russian specificity is considered.

KEYWORDS. Mergers and acquisitions, efficiency evaluation, pharmaceutical market. ARTICLE INFO. Received October 31, 2017; accepted December 19, 2017; available online December 29, 2017.
\end{abstract}

\section{Baikal Research Journal}


Процессы слияния и поглощения компаний на фармацевтическом рынке рассматривались в исследованиях А. И. Балашова и Р. Р. Ишкуловой, по моделированию стоимости фармкомпаний [1, с. 98], Е. В. Болдыревой, Е. Е. Чупандиной, А. А. Бобиной по оценке сделок на фармрынке [2, с. 72], А. М. Измайлова по специфике сделок на мировом фармацевтическом рынке [3, с. 64], Д. Т. Распопова по слияниям и поглощениям компаний на фармацевтическом рынке $[4$, с. 70], И. Широковой по обзору крупнейших сделок M\&A на фармацевтическом рынке, [5, с. 91], У. Штёра по аффилированности компаний на мировом фармрынке [6, с. 52].

Фармацевтический рынок является одним из рынков с развитой конкуренцией $[7$, с. 16], связанной с большим объемом и разнообразием лекарственных средств, большим количеством поставщиков (включая импортеров), значительной взаимозаменяемостью препаратов внутри групп, развитостью аптечных сетей. Усиление конкуренции на фармацевтическом рынке заставляет компании искать новые пути развития [8, с. 234]. Как результат, фармацевтический рынок характеризуется высокой интенсивностью слияний и поглощений (mergers and acquisitions, M\&A), которые открывают компаниям дополнительные возможности $[9$, c. 73$]$.

При выборе метода оценки стоимости компании в первую очередь необходимо опираться на цель оценки и особенности самой компании [10, с. 254]. Выбор метода оценки является очень важным шагом, поскольку разные подходы могут привести к совершенно разным результатам. Такие расхождения могут быть обусловлены как несовершенством рынка, так и результатом сбора неверной информации о компании. В современной теории и практике оценки компаний выделяют три широко применяемых подхода к расчету стоимости бизнеса: доходный, затратный и сравнительный подходы. В свою очередь, в каждом из них выделяют несколько методов, применяемых, в том числе, при оценке в целях М\&A, которые представлены в таблице ниже.

Таблица 1

Подходы и методы оценки колпаний

\begin{tabular}{|l|l|l|}
\hline \multicolumn{1}{|c|}{ Доходный } & \multicolumn{1}{|c|}{ Сравнительный } & \multicolumn{1}{c|}{ Затратный } \\
\hline Метод капитализации доходов & Метод компаний-аналогов & Метод чистых активов \\
\hline $\begin{array}{l}\text { Метод дисконтированных } \\
\text { денежных потоков (DCF) }\end{array}$ & $\begin{array}{l}\text { Метод отраслевых коэффи- } \\
\text { циентов }\end{array}$ & $\begin{array}{l}\text { Метод ликвидационной стои- } \\
\text { мости }\end{array}$ \\
\cline { 2 - 3 } & Метод сделок & \\
\hline
\end{tabular}

Составлено авторами по материалам [10; 11].

Важно отметить, что при анализе подходов и методов к оценке в целях слияний и поглощений выделяют перспективную и ретроспективную оценки. Перспективная оценка дает возможность оценить инвестиционную стоимость компании до осуществления сделки. Ретроспективная оценка, напротив, позволяет оценить целесообразность уже осуществленной сделки, определить была ли достигнута синергия, и, сделать выводы об изменении стоимости компании в результате M\&A сделки. Важно отметить, что перечисленные выше подходы могут равно использоваться как в целях ретроспективной, так и перспективной оценки. Рассмотрим преимущества и недостатки каждого из приведенных подходов подробнее.

\section{Затратный подход}

Наименее используемым при оценке стоимости компаний в целях М\&A является затратный подход. Данный подход включает в себя метод чистых активов и метод ликвидационной стоимости. Методы базируются на определении затрат,

\section{Baikal Research Journal}


требуемых для восстановления либо замещения цели поглощения за вычетом накопленного износа. Наиболее частое применение метод нашел в анализе предприятий, характеризующихся высокой долей основных фондов в стоимости компании. Использование данного подхода в целях слияний и поглощений весьма ограничено, что обусловлено невозможностью оценки синергетического эффекта, поэтому метод может быть применим только в случаях, когда стоимость приобретаемой компании определяется лишь стоимостью ее активов, по причине неспособности бизнеса создавать адекватную нематериальную стоимость. В целом, можно выделить следующие преимущества и недостатки данного подхода:

Преилущества и недостатки затратного подхода

Таблица 2

\begin{tabular}{|l|l|}
\hline \multicolumn{1}{|c|}{ Преимущества } & \multicolumn{1}{|c|}{ Недостатки } \\
\hline $\begin{array}{l}\text { Учитывается влияние производственно-хо- } \\
\text { зяйственных факторов на стоимость активов }\end{array}$ & $\begin{array}{l}\text { Не учитываются возможные перспективы раз- } \\
\text { вития бизнеса и текущая рыночная ситуация }\end{array}$ \\
\hline $\begin{array}{l}\text { Учитывается степень износа активов } \\
\text { при определении уровня развития техноло- } \\
\text { гий }\end{array}$ & $\begin{array}{l}\text { Не учитывается основных финансово-эконо- } \\
\text { мических показателей деятельности объекта } \\
\text { оценки }\end{array}$ \\
\hline Оценка имеет объективную основу & Не учитываются возможные риски \\
\hline
\end{tabular}

Составлено авторами по материалам [10, 11].

Стоит отметить, что структура баланса фармацевтических компаний состоит, в большинстве случаев, из нематериальных активов (патенты, исследования и разработки и пр.), что делает невозможным применение данного метода в исследованиях.

\section{Сравнительный подход}

Данный подход направлен на определение стоимости компании на основании рыночной цены аналогичных предприятий. Применение данного подхода на практике может быть осуществлено только при выполнении нескольких условий. Во-первых, наличие развитого финансового рынка, поскольку сравнительный подход основывается на использовании информации о совершившихся сделках. Во-вторых, наличие на рынке доступа к данным о финансовых показателях компаний, схожих с объектом оценки. В методологии сравнительного подхода выделяют три основных метода оценки стоимости бизнеса - метод компаний-аналогов, метод сделок и метод отраслевых коэффициентов. Как правило, в целях $\mathrm{M} \& \mathrm{~A}$, применяются только первые два метода.

При использовании метода сделок изучаются цены, уплаченные компанией-покупателем за приобретение контроля над компанией-мишенью. Такие сделки носят стратегический характер, поэтому цена сделки также учитывает инвестиционную стоимость. Однако, чтобы получить достоверные результаты при использовании данного метода необходимо наличие информации о поглощенных компаниях, сходных с объектом оценки, кроме того, компании-аналоги должны иметь похожие синергетические эффекты, получаемые от объединения.

Метод компании-аналога оценивает объект, основываясь на цене, по которой схожие компании торгуются на публичных фондовых биржах. По аналогии с методом сделок, применяются коэффициенты, сравнивающие стоимость сделки с показателями финансового состояния и результатов деятельности компании. Несмотря на сложность применения данного метода на практике (обширный анализ отрасли, трудоемкие расчеты), сравнительный подход позволяет с достаточно высокой вероятностью рассчитать инвестиционную стоимость сделки. Более того, полученная стоимость бизнеса будет отражать не только внутреннюю стоимость

\section{Baikal Research Journal}

электронный научный журнал Байкальского государственного университета 
поглощаемой компании, но и возможные синергетические эффекты и конъюнктуру рынка, на котором функционирует объект оценки.

\section{Преимущества и недостатки сравнительного подхода}

\begin{tabular}{|c|c|}
\hline Преимущества & Недостатки \\
\hline $\begin{array}{l}\text { Анализирует реальное соотношения спроса } \\
\text { и предложения, поскольку основывается на } \\
\text { сравнении объекта оценки с уже куплен- } \\
\text { ными аналогами или аналогами, чьи акции } \\
\text { находятся в свободном обращении }\end{array}$ & $\begin{array}{l}\text { Сложность сбора информации о компани- } \\
\text { ях-аналогах ввиду недостаточной развитости } \\
\text { фондового рынка или по причине того, что } \\
\text { аналог является компанией закрытого типа }\end{array}$ \\
\hline $\begin{array}{l}\text { Дает точную оценку, имеющую объективную } \\
\text { рыночную основу при наличии достоверной } \\
\text { информации о компаниях-аналогах }\end{array}$ & $\begin{array}{l}\text { В основе анализа лежит ретроспективная } \\
\text { информация, в то время как перспективы } \\
\text { развития объекта оценки практически не } \\
\text { учитываются }\end{array}$ \\
\hline $\begin{array}{l}\text { Оценка отражает результаты производствен- } \\
\text { но-хозяйственной деятельности компании }\end{array}$ & $\begin{array}{l}\text { Необходимость внесения корректировок в } \\
\text { случае наличия сильных расхождений меж- } \\
\text { ду объектом оценки и компанией-аналогом }\end{array}$ \\
\hline
\end{tabular}

Составлено авторами по материалам $[10 ; 11]$.

\section{Доходный подход}

Доходный подход является наиболее применяемым методом оценки стоимости бизнеса для целей M\&A. Данный метод универсален и лучше других отражает ожидания инвесторов. В рамках доходного подхода стоимость компании определяется исходя из ожидаемых будущих доходов объекта оценки. При использовании данного подхода, как правило, применяется многолетний прогноз, но возможно и использование прогноза на один год. Именно разница в длительности периода прогнозирования является основным различием между двумя методами доходного подхода: методом капитализации доходов и методом дисконтирования денежных потоков.

Метод капитализации денежных доходов чаще всего используется для оценки компании, которая успела накопить активы, имеет стабильное производство и находится на стадии зрелости. Данный метод достаточно прост по сравнению с методом дисконтирования денежных потоков, поскольку не требует долгосрочных прогнозов доходов, однако его применение существенно ограничено по двум причинам: во-первых, не применим к предприятиям, не вышедшим на режим стабильных доходов; во-вторых, данные, необходимые для расчетов, могут являться коммерческой тайной.

Более широкое распространение получил метод дисконтирования денежных потоков. Применение данного метода наиболее целесообразно для учета инвестиционных мотивов, а сделки M\&A, несомненно, относятся к таким мотивам. Любой инвестор стремится приобрести актив, который не только будет приносить доход в будущем и окупит сделанные вложения, но и способствует наращению благосостояния субъекта. Чаще всего метод DCF применяется к относительно молодым компаниям [12, с. 112], находящимся на стадии роста или развития. Несмотря на популярность данного метода, он имеет не только преимущества, но и недостатки.

Таблица 4

\section{Преимущества и недостатки доходного подхода}

\begin{tabular}{|l|l|}
\hline \multicolumn{1}{|c|}{ Преимущества } & \multicolumn{1}{|c|}{ Недостатки } \\
\hline $\begin{array}{l}\text { Учитываются будущие изменения до- } \\
\text { ходов и расходов компании }\end{array}$ & $\begin{array}{l}\text { Неустойчивость экономики увеличивает веро- } \\
\text { ятность неверного прогноза по мере увеличения } \\
\text { прогнозного периода }\end{array}$ \\
\hline
\end{tabular}

\section{Baikal Research Journal}


Окончание табл. 4

\begin{tabular}{|l|l|}
\hline \multicolumn{1}{|c|}{ Преимущества } & \multicolumn{1}{|c|}{ Недостатки } \\
\hline $\begin{array}{l}\text { Учитываются интересы потенциальных } \\
\text { инвесторов, что помогает при при- } \\
\text { нятии решения об инвестировании в } \\
\text { объект оценки }\end{array}$ & $\begin{array}{l}\text { Различные способы вычисления ставок дисконти- } \\
\text { рования и капитализации }\end{array}$ \\
\hline $\begin{array}{l}\text { Учитываются перспективы развития } \\
\text { объекта оценки }\end{array}$ & $\begin{array}{l}\text { Наличие рисков, которые могут оказать суще- } \\
\text { ственное влияние на прогнозируемый доход }\end{array}$ \\
\hline
\end{tabular}

Составлено авторами по материалам [10; 11].

Тем не менее, благодаря тому, что метод DCF позволяет оценить рыночную стоимость бизнеса, отражающую насколько данная компания перспективна, метод денежных потоков является на сегодняшний день самым привлекательным способом оценки для инвесторов, стремящихся вложить средства в прибыльную и перспективную компанию. В исследованиях для расчета стоимости фармацевтических компаний в основном применяют доходный подход, а именно метод дисконтирования денежных потоков, поскольку он позволяет учесть будущие потоки, которые, в свою очередь, обеспечивают функционирование научных лабораторий и исследовательских центров, что является основой развития фармацевтических и биотехнологических компаний.

По оценкам международной аналитической компании «Evaluate Pharma», в 2016 году объем мирового фармацевтического рынка достиг 1125 млрд долларов США1. Положительная динамика мирового фармацевтического рынка обусловлена, главным образом, продолжающимся динамичным ростом крупнейшего рынка - рынка США. В 2015 году его объем увеличился на $6 \%$ и достиг 413 млрд долларов США. Основным фактором влияния на данный тренд стал небывалый рост цен на лекарственные средства - в среднем, в 2015 году, рост уровня цен составил $12,3 \%$.

Проведя анализ сделок по слияниям и поглощениям компаний на мировом фармацевтическом рынке, авторами статьи были выделены наиболее крупные сделки (стоимостью более 5 млрд долларов США). В табл. 5 представлены данные по сделкам слияний и поглощений на мировом фармацевтическом рынке в период 2000-2016 гг.

Таблица 5

Слияния и поглощения на фарлрынке в 2000-2016 годах

\begin{tabular}{|c|l|l|r|}
\hline Год & Компания-покупатель & Объект покупки & Стоимость сделки, млрд дол. \\
\hline \multirow{2}{*}{2000} & Glaxo & SmithKline & 74 \\
\cline { 2 - 4 } & Pfizer & Warner-Lamberts & 88 \\
\hline 2003 & Pfizer & Pharmacia & 61 \\
\hline 2004 & Sanofi & Aventis & 66 \\
\hline \multirow{3}{*}{2007} & Astra-Zeneca & Medimmune & 15,6 \\
\cline { 2 - 4 } & Schering-Plough & Organon & 11 \\
\cline { 2 - 4 } & MerckKgaA & Serono & 10,6 \\
\hline 2008 & Novartis & Alcon & 10,4 \\
\hline \multirow{2}{*}{2009} & Roche & Genentech & 46,8 \\
\cline { 2 - 4 } & Pfizer & Wyeth & 68 \\
\cline { 2 - 4 } & Merck\&Co & Schering-Plough & 41 \\
\hline
\end{tabular}

${ }^{1}$ Обзор тенденций на глобальном и российском фармацевтическом рынке : годовой отчет компании «Evaluate Pharma» : world Preview 2016, Outlook to 2022 (September 2016). URL: http://frprf. $\mathrm{ru} /$ file/Farm.pdf.

\section{Baikal Research Journal}

электронный научный журнал Байкальского государственного университета 


\begin{tabular}{|c|l|l|r|}
\hline Год & Компания-покупатель & Объект покупки & Стоимость сделки, млрд дол. \\
\hline \multirow{3}{*}{2012} & $\begin{array}{l}\text { Bristol-Myers Squibb } \\
\text { Astra-Zeneca }\end{array}$ & $\begin{array}{l}\text { Amylin } \\
\text { Pharmaceuticals }\end{array}$ & 7 \\
\cline { 2 - 4 } & Gilead Sciences Inc & PharmassetInc & 11,2 \\
\hline 2014 & Actavis & Allergan & 66 \\
\hline 2015 & Teva & Allergan generics & 41 \\
\hline \multirow{4}{*}{2016} & Shire & Baxalta & 32,03 \\
\cline { 2 - 4 } & AbbVie & Stemcentrx & 9,80 \\
\cline { 2 - 4 } & Mylan & Meda & 7,20 \\
\cline { 2 - 4 } & Pfizer & AnacorPharmaceuticals & 5,20 \\
\hline
\end{tabular}

Составлено авторами по материалам [3, с. 71-72] и годового отчета компании «Evaluate Pharma». Обзор тенденций на глобальном и российском фармацевтическом рынке : годовой отчет компании «Evaluate Pharma» : world Preview 2016, Outlook to 2022 (September 2016). URL: http://frprf.ru/file/ Farm.pdf.

В 2015 году на мировом фармацевтическом рынке самой крупной сделкой явилось соглашение компаний «Teva» и "Allergan generics business» на общую сумму 41 млрд долларов США. Приобретение портфеля активов другой американской компании «Allergan» стало значимой сделкой для компании «Pfizer». На рис. 1 представлена динамика крупнейших сделок по слияниям и поглощениям на мировом фармацевтическом рынке, начиная с 2000 года.

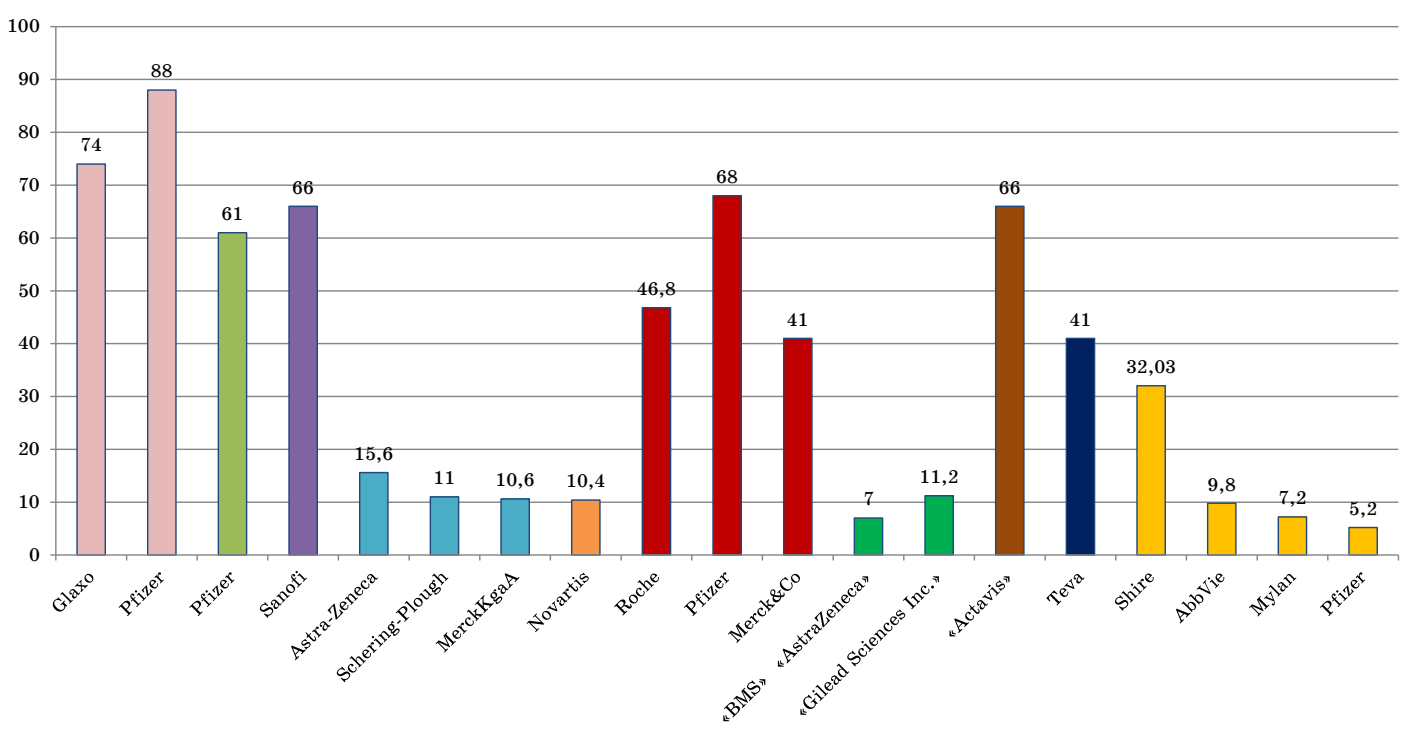

Рис. 1 Динамика крупнейших сделок $М \& A$ на мировом фармрынке в период 2000-2016 гг. (млрд дол.)

(По даннылм табл. 5)

На 2000, 2009 г. и на 2014-2015 года приходится максимальный объем сделок по слияниям и поглощениям (см. табл. 5), как раз на посткризисные периоды в мировой экономике, что видно из рис. 1. Как и ожидалось ранее, в 2016 году продолжилась активность фармацевтических производителей и биотехнологических компаний в сделках по слияниям и поглощениям. Наиболее крупной сделкой за 2016 год считается соглашение о приобретении компанией «Shire» компании

\section{Baikal Research Journal}


«Baxalta» за более чем 32 млрд долларов США (табл. 5). Закрытие данной сделки состоялось в июне 2016 года. Ожидается, что объединенная компания станет крупнейшей в мире в сфере лечения пациентов с редкими заболеваниями. Второй, наиболее значимой M\&A-сделкой 2016 года считается соглашение о приобретении «AbbVie» компании «Stemcentrx» за 9,8 млрд долларов США, о котором было объявлено в апреле 2016 года. По состоянию на 19 июля 2016 года данная сделка была закрыта. Соглашение позволило «AbbVie» заполучить в свой продуктовый портфель перспективного кандидата в препараты "Ровалпитузумабтезирина», предназначенного для терапии мелкоклеточного рака легкого.

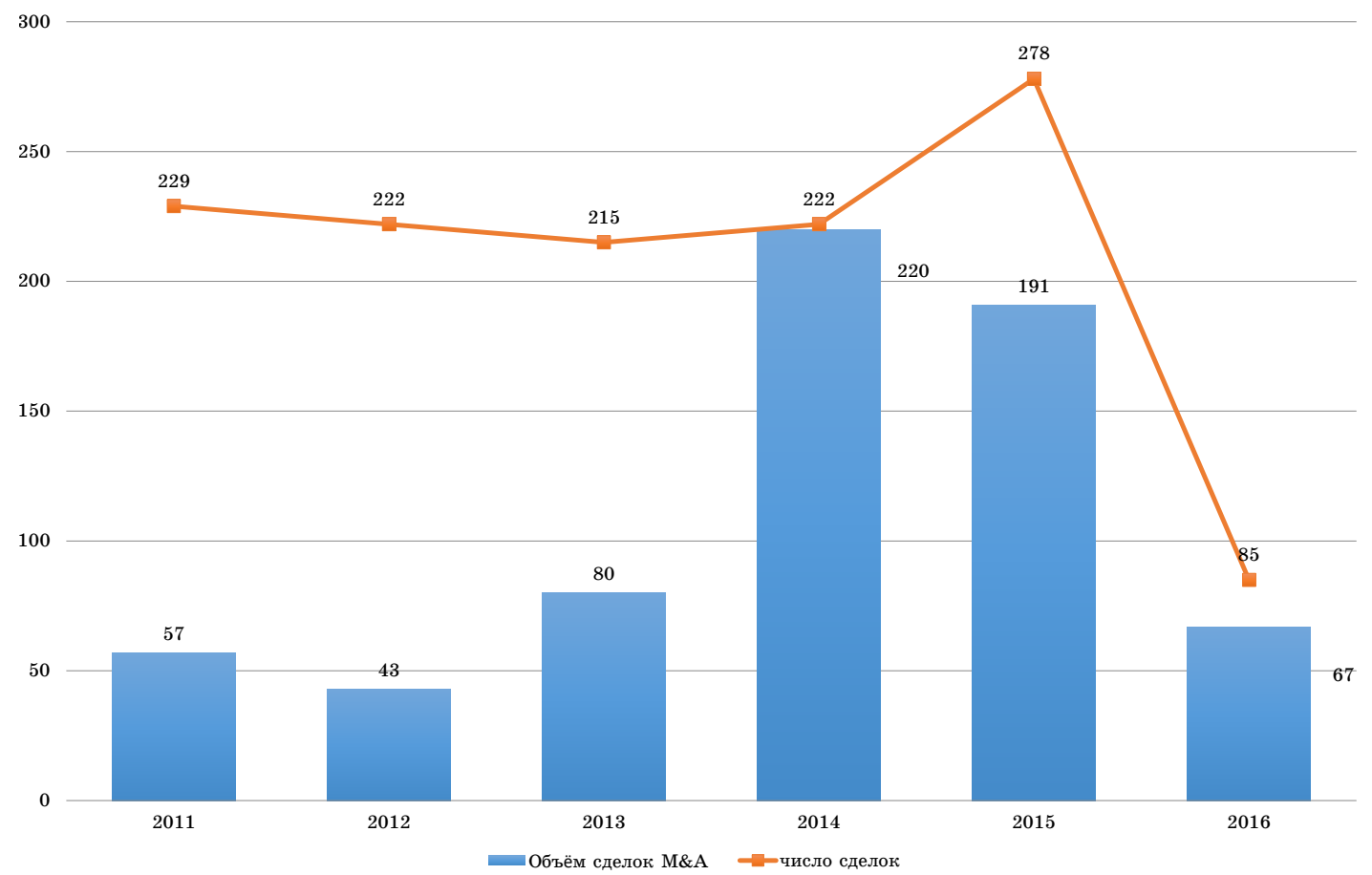

Рис. 2. Сделки М\&А на мировом фармрынке в 2011-2016 г2.

(Обзор тенденций на глобальном и российском фармацевтическом рынке : годовой отчет компании «Evaluate Pharma» : world Preview 2016, Outlook to 2022 (September 2016). URL: http://frprf.ru/file/Farm.pdf)

В феврале 2016 года было объявлено о третьей крупнейшей сделке по итогам первого полугодия - компания «Mylan» объявила о намерении приобрести компанию «Meda» за 7,2 млрд долларов США. Данная сделка позволит «Mylan» выйти на новые для себя рынки с привлекательным и разнообразным продуктовым портфелем, включающим более 2000 оригинальных продуктов, дженериков и OTC-препаратов. Стоит отметить, что в 2014 году компания «Mylan» уже пыталась приобрести «Meda», однако последняя отказалась от предложения, так как один из основных акционеров не согласился на сделку. В мае 2016 года компания «Pfizer» заявила о приобретении компании «Anacor Pharmaceuticals» по цене 99,25 долларов США за одну акцию (общая стоимость сделки составила 5,2 млрд долларов США), а компания «Jazz Pharmaceuticals» сообщила о намерении приобрести своего конкурента - «Celator Pharmaceuticals» за 1,5 млрд долларов США

\section{Baikal Research Journal}


(30,25 долларов США за одну акцию). Необходимо отметить, что средняя сумма сделок по слияниям и поглощениям в первом полугодии 2016 года снизилась по сравнению с аналогичным периодом 2015 года, что неудивительно, учитывая снижение активности фармацевтических компаний в М\&A-сфере.

В перспективе в российской фармацевтической промышленности ожидается увеличение числа сделок по слияниям и поглощениям с участием как зарубежных, так и ведущих отечественных фармацевтических компаний [13]. Тенденции роста сделок M\&A в отечественной фармацевтической промышленности отражают глобализационные процессы $[14$, с. 148] в мировой фармацевтической индустрии, они будут нарастать в связи с ужесточением глобальной конкуренции на мировом фармацевтическом рынке.

Приобретение иностранными фармацевтическими компаниями отечественных фармпроизводств обусловлено законодательными инициативами по импортозамещению [15, с. 72]. Можно ожидать сделок M\&A как в сегменте производства, так и в розничном сегменте. Однако, на российском фармацевтическом рынке очень мало серьезных объектов для поглощения с учетом того, что ценность для потенциальных покупателей представляют не заводы, а портфели. То есть на фармацевтическом рынке Российской Федерации, с одной стороны, имеется избыток производственных мощностей, a с другой - дефицит мощностей для проведения R\&D.

Инновационное развитие требует серьезных инвестиций в изобретения, испытания и апробацию новых лекарственных средств. В настоящее время Институт биоорганической химии $\mathrm{PAH}$, а также Тихоокеанский институт биоорганической химии Дальневосточного отделения РАН, Дальневосточный федеральный университет ведут активную работу по использованию природных токсических соединений при разработке инновационных лекарственных препаратов и внедрения их в клиническую практику. Работы в области инновационных систем доставки лекарственных средств ведутся во многих академических институтах, а также в нескольких университетских исследовательских центрах, включая НИИ Физико-химической биологии им. Белозерского при МГУ, многие базовые институты МФТИ, а также отдельные частные компании, например, центр высоких технологий «Химрар». В общем данная отрасль биофармацевтических технологий находится в России в прогрессирующем состоянии.

Таким образом, в результате изучения оценок эффективности процессов слияний и поглощений на фармацевтическом рынке, авторами сделан вывод, что в исследованиях для расчета стоимости фармацевтических компаний в основном применяют доходный подход, а именно метод дисконтирования денежных потоков. Поскольку он позволяет учесть будущие потоки, которые, в свою очередь, обеспечивают функционирование научных лабораторий и исследовательских центров, что является основой развития фармацевтических и биотехнологических компаний. Кроме того, необходимо отметить, что процессы слияний и поглощений на мировом фармацевтическом рынке обусловлены, прежде всего, попытками компаний интенсифицировать процессы разработки оригинальных лекарственных средств, с целью экономии издержек, которые направлены на процесс R\&D.

\section{Список использованной литературы}

1. Балашов А. И. Моделирование стоимости фармацевтической компании в процессах слияния и поглощения на рынке / А. И. Балашов, Р. Р. Ишкулова // Менеджмент в России и за рубежом. -2015 . - № 1. - С. 97-104.

2. Болдырева Е. В. Процессы слияния и поглощения на фармацевтическом рынке: состояние, оценка / Е. В. Болдырева, Е. Е. Чупандина, А. А. Бобина // Пути и формы совершенствования фармацевтического образования. Поиск новых физиологически актив-

\section{Baikal Research Journal}

электронный научный журнал Байкальского государственного университета 
ных веществ : материалы 4-й Всерос. с междунар. участием науч.метод. конф. «Фармобразование-2010», Воронеж, 20-22 апр. 2010 г. - Воронеж : Изд-во Воронеж. гос. ун-та, 2010. - Ч. 2. - C. 70-74.

3. Евстратов А. В. Слияния и поглощения компаний на фармацевтическом рынке: мировой опыт и российская специфика : монография / А. В. Евстратов, А. М. Измайлов. Волгоград : Изд-во ВолгГТУ, 2016. - 156 с.

4. Распопов Д. Т. Слияния и поглощения на мировом фармацевтическом рынке / Д. Т. Распопов // Международная экономика. - 2014. - № 8. - С. 69-74.

5. Широкова И. В фокусе - слияния и поглощения / И. Широкова // Ремедиум. 2014. - № 10. - С. 91 .

6. Штёр У. Кто есть кто в мире Фармы, или Загадочные переплетения интересов мировых фармацевтических компаний / У. Штёр // Рецепт. - 2012. - № 1. - С. 49-56.

7. Воронцова Н. А. Сущность и специфические особенности фармацевтического рынка [Электронный ресурс] / Н. А. Воронцова // Baikal research journal. - 2016. - T. 7, № 3. - DOI : 10.17150/2411-6262.2016.7(3).16. - Режим доступа: http://brj-bguep.ru/ reader/article.aspx $? \mathrm{id}=20773$.

8. Измайлов А. М. Методический подход к анализу конкурентоспособности фармацевтического промышленного предприятия / А. М. Измайлов // Бизнес в законе. — 2015. № 3 . - С. $232-236$.

9. Карачев И. А. Развитие российского фармацевтического рынка на современном этапе / И. А. Карачев // Вестник Самарского государственного экономического университета. - 2016. - № 8 (142). - С. 71-77.

10. Депамфилис Д. Слияния, поглощения и другие способы реструктуризации компании / Д. Депамфилис. - М. : Олимп-Бизнес, 2007. - 960 с.

11. Садовская Т. Г. Оценка стоимости бизнеса и синергетических эффектов при создании и реорганизации корпораций в современных условиях глобализации / Т. Г. Садовская // Аудит и финансовый анализ. - 2011. - № 6. - С. 226-240.

12. Оценка бизнеса : учебник / под ред. А. Г. Грязновой, М. А. Федотовой. - М. : Финансы и статистика, 2009. - 736 с.

13. Кунев С. В. Проблемы и пути развития российской фармацевтической отрасли в условиях внешнеэкономических ограничений / С. В. Кунев, Л. В. Кунева // Современные проблемы науки и образования. - 2014. - № 6. - С. 363.

14. Косякова И. В. Интернационализация мировой экономики и реализация концепции устойчивого развития / И. В. Косякова // Проблемы экономики. — 2007. — № 1. C. $146-152$.

15. Третьякова Е. А. Состояние и перспективы инновационного развития российской фармацевтической промышленности / Е. А. Третьякова, Е. В. Шилова // Управление экономическими системами. - 2012. - № 4 (40). — С. 72.

\section{References}

1. Balashov A. I., Ishkulova R. R. Modeling the Cost of the Pharmaceutical Company in the Process of Mergers and Acquisitions on the Market. Menedzhment $v$ Rossii $i$ za rubezhom = Management in Russia and Abroad, 2015, no. 1, pp. 97-104. (In Russian).

2. Boldyreva E. V., Chupandina E. E., Bobina A. A. Processes of mergers and acquisitions on the pharmaceutical market. Puti $i$ formy sovershenstvovaniya farmatsevticheskogo obrazovaniya. Poisk novykh fiziologicheski aktivnykh veshchestv. Materialy $4^{\text {th }}$ Mezhdunarodnoi nauchno-prakticheskoi konferentsii, Voronezh, aprelya $2010 \mathrm{~g}$. [Ways and forms of mastering pharmaceutical education. Search for new physiologically active substances. Materials of $4^{\text {th }}$ International Research Conference, Voronez, april 2010]. Voronez State University Publ., 2010, iss. 2, pp. 70-74. (In Russian).

3. Evstratov A. V., Izmailov A. M. Sliyaniya $i$ pogloshcheniya kompanii na farmatsevticheskom rynke: mirovoi opyt i rossiiskaya spetsifika [Mergers and Acquisitions in the Pharmaceutical Market: International Experience and Russian Specific]. Volgograd State Technikal University Publ., 2016. 156 p.

4. Raspopov D. T. Mergers and acquisitions on the world pharmaceutical market. Mezhdunarodnaya ekonomika = The World Economics, 2014, no. 8, pp. 69-74. (In Russian).

\section{Baikal Research Journal}


5. Shirokova I. In the focus - mergers and acquisitions. Remedium $=$ Remedium, 2014, no. 10, p. 91. (In Russian).

6. Shter U. Who is who in the world of Pharma, or mystical entwinements of interests of the world pharmaceutical companies. Retsept = Prescription, 2012, no. 1, pp. 49-56. (In Russian).

7. Vorontsova N. A. Nature and specific features of pharmaceutical market. Baikal research journal, 2016, vol. 7, no. 3. DOI : 10.17150/2411-6262.2016.7(3).16. Available at: http://brj-bguep.ru/reader/article.aspx?id=20773. (In Russian).

8. Izmailov A. M. Methodical Approach to the Analysis of the Competitiveness of the Pharmaceutical Industry Enterprises. Biznes $v$ zakone = Business in Law, 2015, no. 3, pp. 232-236. (In Russian).

9. Karachev I. A. Development of Russian pharmaceutical market at the present stage. Vestnik Samarskogo gosudarstvennogo ekonomicheskogo universiteta = Vestnik of Samara State University of Economics, 2016, no. 8 (142), pp. 71-77. (In Russian).

10. Depamfilis D. Sliyaniya, pogloshcheniya $i$ drugie sposoby restrukturizatsii kompanii [Mergers, acquisitions and other ways of company restructuring]. Moscow, Olimp-Biznes Publ., 2007. 960 p.

11. Sadovskaya T. G. Business Valuation and Synergy Estimation for Corporate Development and Reorganization in Recent Globalization Environment. Audit $i$ finansovyi analiz $=$ Audit and Financial Analysis, 2011, no. 6, pp. 226-240. (In Russian).

12. Gryaznova A. G., Fedotova M. A. (eds). Otsenka biznesa [Evaluation of business]. Moscow, Finansy i statistika Publ., 2009. 736 p.

13. Kunev S. V., Kuneva L. V. Problems and Directions of Development of the Russian Pharmaceutical Industry in Terms of Foreign Restrictions. Sovremennye problemy nauki $i$ obrazovaniya = Modern problems of science and education, 2014, no. 6, pp. 363. (In Russian).

14. Kosyakova I. V. Internationalization of world economy and implementation of sustainable development concept. Problemy ekonomiki $=$ The problems of economy, 2007, no. 1, pp. 146-152. (In Russian).

15. Tretyakova E. A., Shilova E. V. Condition and Prospects of Innovative Development of the Russian Pharmaceutical Industry. Upravlenie ekonomicheskimi sistemami = Management of economic systems, 2012, no. 4 (40), pp. 72. (In Russian).

\section{Информация об авторах}

Евстратов Александр Владимирович - кандидат экономических наук, доцент кафедры экономики и финансов, Волгоградский институт управления - филиал РАНХиГС, 400131, Волгоград, ул. Гагарина, 8, e-mail: evstratov.mail@gmail.com.

Гончарова Александра Евгеньевна - магистрант кафедры мировой экономики и экономической теории, Волгоградский государственный технический университет, г. Волгоград, 400005, Волгоград, пр. им. Ленина, 28, e-mail: 15_sandra_95@mail.ru.

\section{Authors}

Aleksandr V. Evstratov - PhD in Economics, Associate Professor, Chair of Economics and Finance, Volgograd Institute of Management, 8 Gagarin St., 400131, Volgograd; e-mail: evstratov.mail@gmail.com.

Aleksandra Ye. Goncharova - Master Degree Student, Chair of World Economy and Economic theory, Volgograd State Technical University, Volgograd; e-mail: 15_sandra_95@mail.ru.

\section{Для цитирования}

Евстратов А. В. Обоснование эффективности процессов слияний и поглощений на фармацевтическом рынке: мировой опыт и российская специфика / А. В. Евстратов, А. Е. Гончарова // Baikal Research Journal. - 2017. — T. 8, № 4. - DOI : 10.17150/2411-6262.2017.8(4).20.

\section{For Citation}

Evstratov A. V., Goncharova A. Ye. Substantiation of Efficiency of Mergers and Acquisitions Processes in the Pharmaceutical Market: World Experience and Russian Specificity. Baikal Research Journal, 2017, vol. 8, no. 4. DOI: 10.17150/2411-6262.2017.8(4).20. (In Russian).

\section{Baikal Research Journal}

